\title{
A first acoustic density estimate for sperm whales in Irish offshore waters
}

\author{
Jonathan Gordon ${ }^{1}$, Douglas Gillespie ${ }^{1}$, Russel Leaper $^{2}$, Arthur LeE $^{3}$, Lindsay Porter ${ }^{3}$, JoAnne O’Brien $^{4}$, Rossa MeAde $^{4}$, \\ Oliver Ó CADHLA AND SiMON BERROW ${ }^{4}$
}

Contacte-mail:jg20@st-andrews.ac.uk

\begin{abstract}
Previous studies off western Ireland have suggested that substantial numbers of, mainly male, sperm whales may be found in these habitats. Whaling vessels operating from shore stations in Ireland in the early $20^{\text {th }}$ century frequently caught sperm whales in oceanic waters. It is likely that this North Atlantic region contains important foraging habitats for this species, and that mature males must also migrate through this area moving between breeding grounds to the south and other feeding areas further north. Increasingly, these offshore waters are being utilised and potentially impacted by human industrial activities. For example, as inshore resources are depleted and technology improves, both the commercial fishing and the oil and gas industry are becoming more active in deeper waters beyond the continental margin. It is important therefore to better understand the biology and ecology of sperm whales in these more remote areas. However, their offshore location and deep diving habits, together with weather constraints in the exposed Atlantic, make research difficult. New sperm whale density estimates are reported using data from six seasonal passive acoustic surveys carried out in two successive years (2015 and 2016). These covered a corridor approximately $110 \mathrm{~km}$ wide which bounded a major portion of Ireland's continental shelf break. Towed hydrophone line-transect methodologies were used, which have proven to be highly effective for surveying sperm whales in offshore waters and in poor weather conditions. Target motion analysis was applied to calculate the ranges of vocalising whales from the survey tracklines and the effective strip half-width calculated across all surveys was $7,958 \mathrm{~m}$. The study area was surveyed in three blocks and animal densities within these blocks varied between 1 and 4.6 individuals per $1,000 \mathrm{~km}^{2}(\mathrm{CV} 0.34$ and 0.21 respectively) with an overall mean density in waters deeper than $300 \mathrm{~m}$ of 3.2 individuals per $1,000 \mathrm{~km}^{2}$ (CV 0.04 ). These robust density estimates are the first of their kind for Irish waters and are similar to those reported in other Atlantic areas considered significant for this species. These results emphasise the significance of this region as sperm whale habitat. The results of this study should be used to inform the future sustainable development and management of Ireland's offshore Atlantic.
\end{abstract}

KEYWORDS: ABUNDANCE ESTIMATE; ACOUSTICS; ATLANTIC OCEAN; MONITORING; NORTHERN HEMISPHERE; SPERM WHALE; SURVEY-VESSEL

\section{INTRODUCTION}

Sperm whales (Physeter macrocephalus) are the largest of the toothed whales and the biggest predator operating in many lower mesopelagic and bathypelagic ecosystems. They are also thought to be ecologically important within these ecosystems and their significance may well increase as previously over-exploited populations return towards preexploitation levels (Katona and Whitehead, 1988). It has been suggested that, as they primarily feed at depth yet defecate at the surface, sperm whales could enhance primary productivity in some areas by transporting key nutrients from the deep ocean into the photic zone (Doughty et al., 2016; Lavery et al., 2010). Despite their large size and ecological importance, often, little is known about local sperm whale populations. Sperm whales inhabit the comparatively deep waters off continental shelf edges and the open ocean; they are rarely found in waters less than $200 \mathrm{~m}$ deep (Whitehead, 2003). In countries with a large continental shelf, such as Ireland, sperm whales may rarely come within $100 \mathrm{~km}$ of the shore. Thus, they will seldom be encountered opportunistically at sea and whale mortalities occurring offshore will only rarely strand along the coast. Further, because foraging sperm whales perform long dives and spend most of their time underwater, they are very difficult to observe, so conducting quantitative population surveys of the species in exposed Atlantic environments can be particularly challenging. Sperm whales are however extremely vocal, producing long trains of characteristic clicks for most of the time that they are foraging. These clicks can be detected at ranges of several miles using simple towed and directional hydrophones. Thus, passive acoustic methods can compensate for the whales' poor surface availability and these techniques have been key to both studying live sperm whales at sea (Whitehead and Gordon, 1986) and for conducting quantitative population surveys (Barlow and Taylor, 2005; Leaper et al., 1992; Lewis et al., 2018).

As male sperm whales mature, they leave the 'mixed' groups of females and young males in which they were born and live increasingly solitary lives at higher latitudes. Female sperm whales are rarely encountered north of $45^{\circ}$ in the northeast Atlantic (Evans, 1997) and the majority of sperm whales encountered in Irish waters are therefore likely to be mature or maturing males (Wall et al., 2013). For example, nineteen of the twenty sperm whales stranded in Ireland for which gender was determined were males (Berrow and Rogan, 1997) while Ó Cadhla et al. (2004) reported only three calves in a total of 56 sperm whale sightings reported by experienced observers. A young calf that

\footnotetext{
${ }^{1}$ Sea Mammal Research Unit, Scottish Oceans Institute, University of St Andrews, East Sands, St Andrews, KY16 8LB, UK.

${ }^{2}$ Canal House, Banavie, Fort William, PH33 7LY, UK.

${ }^{3}$ Southeast Asia Marine Mammal Research (SEAMAR), 17F, Tower One, Lippo Centre, Admiralty, Hong Kong SAR.

${ }^{4}$ Marine and Freshwater Research Centre, Galway-Mayo Institute of Technology, Dublin Road, Galway, H91 T8NW, Ireland.

${ }^{5}$ National Parks and Wildlife Service, Department of Culture, Heritage and the Gaeltacht, Galway, Ireland.
} 
stranded alive in Ireland in 2004 (Berrow and O'Brien, 2005) was considered very unusual but this event, and Ó Cadhla et al. (2004), suggest that females and their young do occasionally occur in Irish waters.

It is clear from a range of sources that potentially significant numbers of sperm whales are present in the offshore waters of Ireland and Scotland. One of the most substantive efforts to survey Irish offshore waters was the 'Cetaceans and Seabirds of Ireland's Atlantic Margin' project which, between 1999 and 2000, collected both visual and acoustic data from a range of vessels of opportunity and completed one dedicated summer line-transect survey (SIAR in 2000). Sperm whales were the most frequently sighted of the great whales and detections were widely distributed in waters greater than 200m (Ó Cadhla et al., 2004). Towed hydrophone surveys were also conducted from platforms of opportunity as part of the same project (Aguilar de Soto et al., 2004). This methodology provided both a better detection range and the ability to monitor during both day and night, and in the high sea-states which are commonplace in this part of the Atlantic. Some 14,478km of trackline with acoustic effort were completed in this study. The offshore coverage was particularly good, extending throughout much of the Rockall Trough and covering the eastern edge of the Rockall Bank. A total of 110 acoustic encounters with sperm whales were logged (Aguilar de Soto et al., 2004). Sperm whales were encountered throughout the deeper waters with highest relative densities in waters over the shelf edge and the eastern margin of the Rockall Trough. More recently, Wall et al. (2013) analysed data from 1,078 days of visual survey effort aboard research vessels, Irish Naval Service vessels and commercial ferries between 2005 and 2011. Sperm whale sightings occurred almost exclusively in the Rockall Trough. All sightings of sperm whales were recorded in waters $>500 \mathrm{~m}$ deep beyond the edge of the Irish continental shelf, with the majority occurring in waters $>1 \mathrm{~km}$ deep. Indeed, in this study sperm whales constituted Ireland's most widespread and abundant deep-water whale species and the species was considered to possibly be the most abundant large whale within the Irish EEZ (Wall et al., 2013).

There has not been such a well-coordinated effort to collect offshore cetacean data in UK waters but several studies indicate that sperm whales can be found there in similar deep-water habitats and in substantial numbers. Some of these studies used sightings made during 'seabirds at sea' surveys (Reid et al., 2003; Weir et al., 2001) and observations made during seismic exploration surveys (Stone, 2015). The waters around the Wyville Thomson ridge, an extensive raised seafloor feature lying between the Faroe-Shetland Channel and the Rockall Trough, might have particularly high densities. An early acoustic survey in the winter of 1997-98 showed high sperm whale encounter rates to the south of the Wyville Thomson Ridge and to the east of the Rosemary Bank lying southwest of the ridge (Lewis et al., 1998). Opportunistic acoustic monitoring has also been carried out from vessels conducting oceanographic surveys to the west of Scotland and into the Rockall Trough, and between Shetland and the Faroe Islands (Embling, 2007; Hastie et al., 2001; Hastie et al., 2003). Embling (2007) developed predictive models for the area using these monitoring data, while Hastie et al. (2003) calculated density estimates for sperm whales in the Faroe-Shetland Channel.

There have been few surveys in either Irish or UK waters capable of generating density estimates for sperm whales. In the summer of 2007 two surveys of offshore waters, using compatible methods, took place in the northeast Atlantic. The Cetacean Offshore Distribution and Abundance in the European Atlantic (CODA) project covered offshore waters west of the Atlantic seaboard of Spain, France, Ireland and the UK (Hammond et al., 2009) while the Trans-North Atlantic Sightings Survey (T-NASS) covered a relatively high proportion of the North Atlantic (Pike et al., 2008). Rogan et al. (2017) combined data from both surveys to provide density and abundance estimates for sperm whales that included the area to the west of Ireland. Towed hydrophone surveys were also carried out during CODA though unfortunately the vessel that covered the majority of Irish waters was too noisy for Passive Acoustic Monitoring (PAM) to be successful. Data from survey blocks further to the south, however, were analysed to provide acousticallybased density estimates for sperm whales (Hammond et al., 2009).

Historically, northeast Atlantic sperm whales were taken by commercial whaling operations in Iceland, Norway, Scotland, Ireland, Spain and Portugal and by open-boat whalers in the Azores and Madeira (Avila de Melo and Martin, 1985; Brown, 1976; Tønnessen and Johnsen, 1982). Whaling operations from shore stations in western County Mayo, Ireland caught 63 male sperm whales between 1908 and 1922 (Fairley, 1981). The catches were from waters covered by the survey reported here, while whalers operating from Harris in the Outer Hebrides, UK caught 76 male sperm whales between 1904 and 1928 in waters just north of the area covered by our survey (Brown, 1976). Brown (1976) commented that sperm whale catches were higher when fin whales, which were the primary target for these whaling operations, were scarce and/or the price for sperm whale oil was high. Now that these activities have been absent for 90 years a phase of population recovery might be expected. However, the lack of reliable historical information on numbers and densities, and the scarcity of more recent estimates means it is not possible to confirm if this is the case.

Human maritime activities are likely to have an increasing impact on marine waters and ecosystems beyond the continental shelf, as some resources (e.g. fish stocks) closer to shore are depleted, and as technological advances allow resource exploitation in deeper oceanic waters. In this regard Davies et al. (2007) reviewed emerging threats to deep-sea habitats and emphasised deep-water fishing, and oil and gas exploration and exploitation, as being of particular concern. Documented sperm whale habitat along the Atlantic Margin to the west of Ireland largely overlaps with areas which are now of growing interest to the oil and gas industry regarding their potential for resource extraction. The impact on marine mammals of some of the industry's activities, in particular seismic surveying which uses intense underwater sound sources over protracted periods, is a cause of concern (Gordon et al., 2003; Harwood and Wilson, 2001; Wright and Mel Cosentino, 2015). In this regard a knowledge of sperm whale density and distribution is important for 
understanding, managing and mitigating potentially negative impacts on the species. The need for robust and contemporary primary data to inform management and conservation provided the motivation for the current study.

Towed hydrophone line-transect surveys, which apply target motion analysis to estimate the range of vocalising whales from the trackline, have been used to estimate sperm whale densities for more than two decades (Barlow and Taylor, 2005; Fais et al., 2016; Leaper et al., 1992; Leaper et al., 2000; Leaper et al., 2003; Lewis et al., 2007; Lewis et al., 2018). Here, this methodology was applied to calculate the absolute density of sperm whales in Irish offshore Atlantic waters, largely following the approach of the most recent of these studies (Lewis et al., 2018).

\section{MATERIALS AND METHODS}

\section{Survey area}

The survey area for this study was a corridor approximately $110 \mathrm{~km}$ wide and straddling the Irish continental shelf break, running from a point just South of the mouth of the Porcupine Seabight (approx. $49^{\circ} \mathrm{N}, 13^{\circ} \mathrm{W}$ ) to the north- western limit of the Irish continental shelf break (approx. $56^{\circ} \mathrm{N} 9^{\circ} 30 \mathrm{~W}$ ) (Fig. 1). This area was divided into three blocks within which a series of zig-zag survey tracklines were placed to achieve a near-even coverage probability. In order to avoid prior assumptions regarding the importance of waters along the continental shelf break for deep-diving species, each survey block contained substantial areas overlying the continental shelf in addition to continental slope and deeper basin waters. The northernmost block, $\mathrm{N}$ $(52,786 \mathrm{~km} 2)$ was surveyed in the spring, summer and autumn of 2015 while the two more southern blocks, S1 $(31,346 \mathrm{~km} 2)$ and $\mathrm{S} 2(34,578 \mathrm{~km} 2)$ were surveyed in the spring, summer and autumn of 2016.

\section{Towed hydrophone surveys}

Six towed hydrophone surveys were carried out between May and October, three in 2015 (Block N) and three in 2016 (Blocks S1 and S2) (Table 1). Two survey vessels were used: two surveys were carried out on Ireland's RV Celtic Voyager, a $31 \mathrm{~m}$ research vessel operated by Ireland's Marine Institute, while four surveys were carried out using the RV Song of the

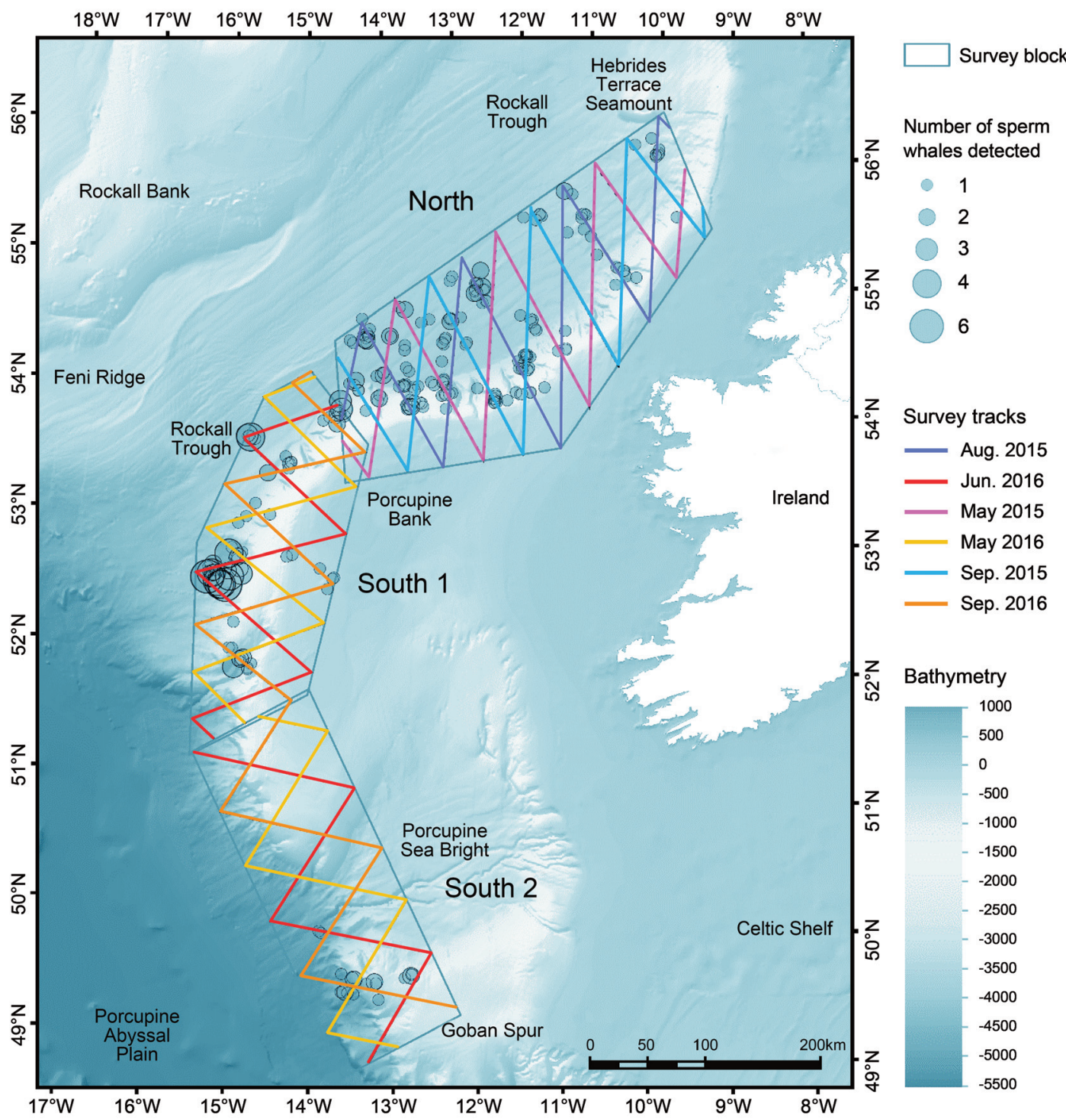

Fig. 1. Survey blocks, transect lines and primary acoustic sperm whale detections for ObSERVE Acoustic surveys, $2015-16$. The northern region was considered a single survey block 'North', while the geometry of the continental shelf break in the southern region required two survey blocks 'South 1' and 'South 2'. Block 'North' was covered three times by surveys in 2015 while blocks 'South 1' and 'South 2' were each covered by three surveys in 2016. 
Table 1

Summary of total survey effort for the PAM towed array surveys conducted in 2015 and 2016.

\begin{tabular}{lllcc}
\hline Survey & Dates & \multicolumn{1}{c}{ Vessel } & $\begin{array}{c}\text { Survey track length } \\
\text { (n.miles) }\end{array}$ & $\begin{array}{c}\text { No. of sperm whale acoustic } \\
\text { detection events }\end{array}$ \\
\hline PAM 1 & 7-14 May 2015 & RV Celtic Voyager & 610 & 87 \\
PAM 2 & 24-29 Aug. 2015 & RV Song of the Whale & 623 & 86 \\
PAM 3 & 22-27 Sep. 2015 & RV Song of the Whale & 626 & 69 \\
PAM 4 & 18-24 May 2016 & RV Celtic Voyager & 630 & 5 \\
PAM 5 & 20-29 June 2016 & RV Song of the Whale & 634 & 84 \\
PAM 6 & 05-10 Oct. 2016 & RV Song of the Whale & 661 & 60 \\
\hline
\end{tabular}

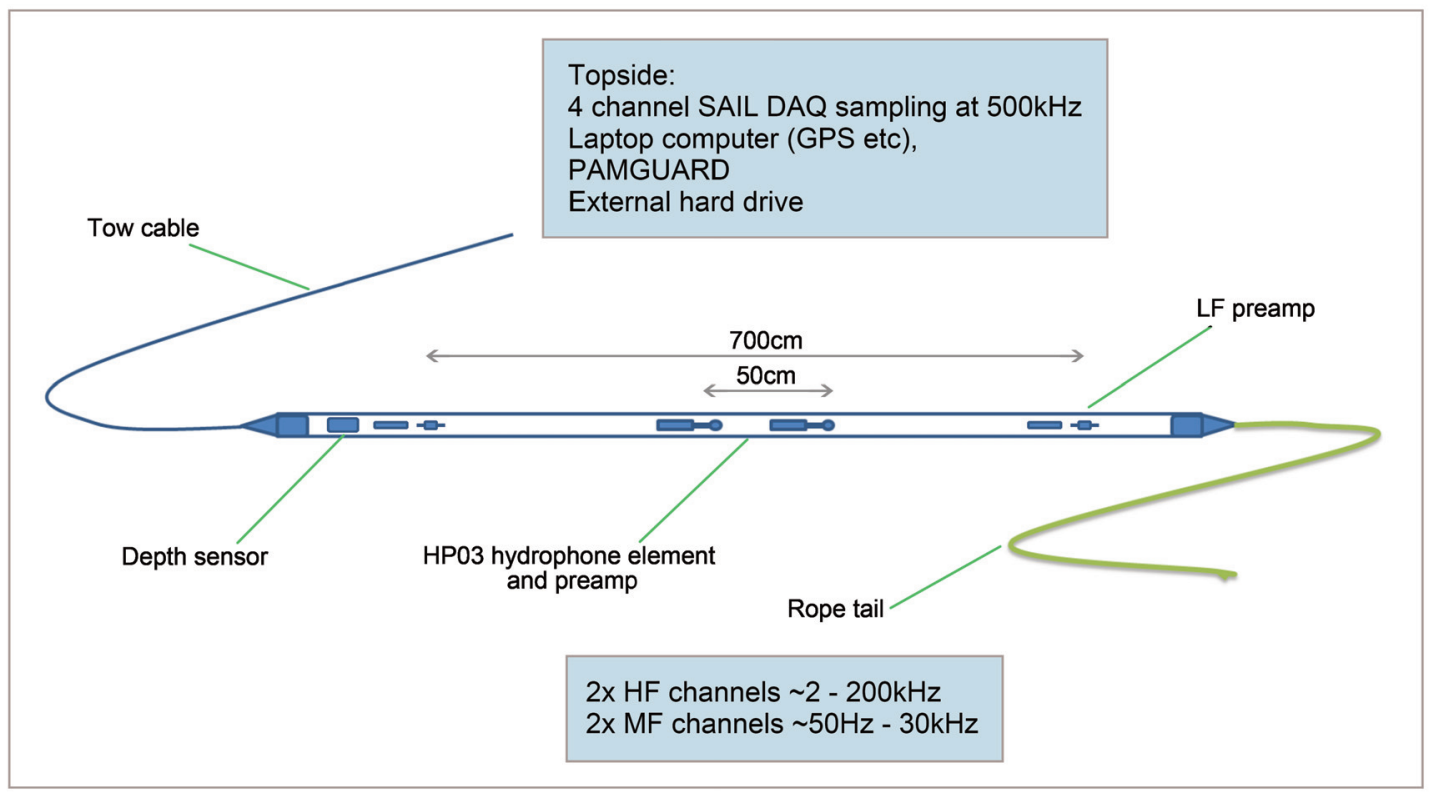

Fig. 2. The Towed PAM system deployed during ObSERVE Acoustic surveys.

Whale, a $21 \mathrm{~m}$ motor sailing-vessel operated by Marine Conservation Research (UK).

\section{Survey design}

A series of transect lines were generated within each survey block using the survey design module in the Distance v.6.2 software package (Thomas et al., 2010), specifying a zig-zag survey design aligned across the general axis of the major depth contours. A minimum of 600 n.miles of survey effort was required during each survey as part of the commissioned contract. Available survey effort was allocated between the two southern blocks (S1 and S2) in proportion to each block's total area. Having established a randomly-positioned transect line within each block using the Distance software, two additional sets of transects were generated for each survey block by hand, with evenly spaced tracks running nearparallel to the first randomised set so that the block was covered evenly across all surveys (Fig. 1). The surveys' zigzag design allowed for the efficient use of boat time but it resulted in a small amount of effort/strip overlap at the turning points. The extent of this overlap given the effective strip halfwidth measured in this survey $(7,958 \mathrm{~m})$ was explored using GIS tools. The average overlaps were $5.5 \%$ for surveys in the North block $(\mathrm{N})$, and $3.6 \%$ and $2.3 \%$ for blocks S1 and S2 respectively. These overlaps will not cause any bias in the point estimates of density. They are equivalent to a low level of random resampling of survey segments which may result in a very slight underestimation of variance.
Surveys were conducted at an average vessel speed of $8 \mathrm{kn}$. Efforts were made to maintain this speed in different weather and current conditions while minimising vessel-generated noise. Acoustic data were collected whenever possible while the vessels were in offshore waters, including during transits to and from prescribed transect lines. However, for this analysis only data collected on survey tracklines within the survey blocks have been included.

\section{Equipment}

Acoustic data were collected using a towed hydrophone array (Vanishing Point Ltd, Plymouth UK). This comprised a $10 \mathrm{~m}$ oil-filled streamlined sensor section towed via $340 \mathrm{~m}$ of Kevlar-strengthened tow cable. The streamer section contained four hydrophone elements (Fig. 2): a matched pair of 'low frequency' elements and preamplifiers (Benthos AQ4 elements and Magrec HP02 preamplifiers with a $50 \mathrm{~Hz}$ low cut filter) spaced $7 \mathrm{~m}$ apart, and two 'high frequency' hydrophone element and preamplifier units (Magrec HP03 with $2 \mathrm{kHz}$ low cut filter) separated by $50 \mathrm{~cm}$. Nominal frequency responses of the low and high frequency elements and associated preamplifiers were $50 \mathrm{~Hz}$ to $40 \mathrm{kHz}$ and $2 \mathrm{kHz}$ to $200 \mathrm{kHz}$ respectively. Hydrophone depth information was provided using a Keller PA-9SE-10 pressure sensor.

Above water, output from each hydrophone was connected to the input of a four-channel SAIL data acquisition card (St Andrews Instrumentation Ltd, Tayport, UK). This unit applied adjustable analogue filtering and gain before 


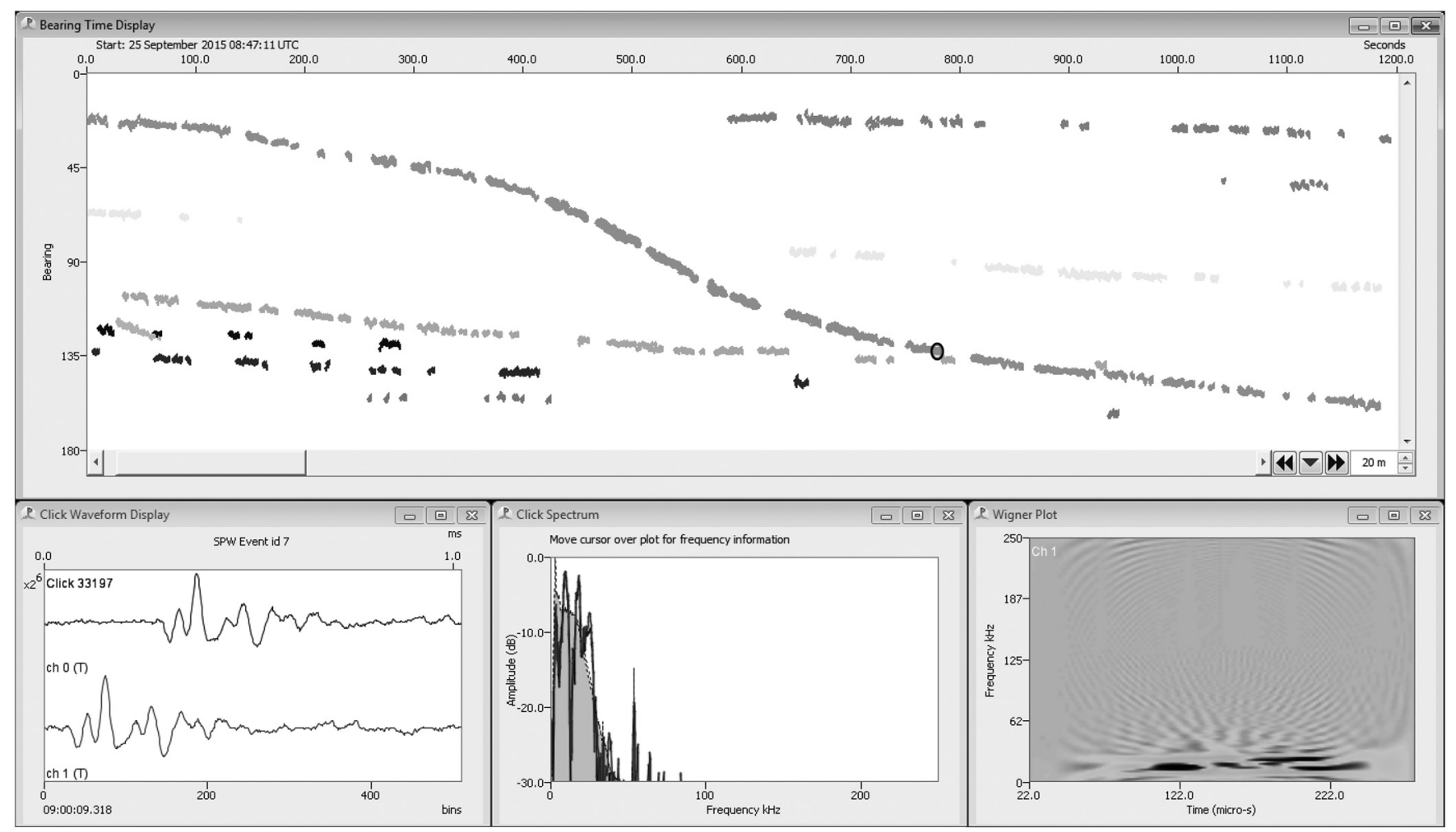

Fig. 3. PAMGuard click detector display showing bearing vs time for $20 \mathrm{~min}$ of data as the hydrophone array is towed past 8 vocalising whales. All non-sperm whale clicks have been removed from the display. The click waveform, spectrum and Wigner plot are shown for one click (circled) in the centre of the display.

sampling each channel at $500 \mathrm{kHz}$. Data were written to hard disk drives as four channel .wav files using the software PAMGuard (Gillespie et al., 2008) available via http://www.pamguard.org. In addition, PAMGuard logged the ship's GPS position and true heading once per second and read and stored the hydrophone depth from the output of a Measurements Computing USB 1208LS digitiser. PAMGuard was primarily configured to record audio and GPS data for later offline analysis. However, for quality control and for real-time monitoring purposes, additional PAMGuard modules were configured to: (a) display spectrograms of the high frequency $(500 \mathrm{kHz})$ data and a decimated $(50 \mathrm{kHz})$ data stream, allowing operators to check for tonal noises and to view acoustic data in real time; and (b) run a 'click detector' set to trigger on all transient sounds with energy above $5 \mathrm{kHz}$ and to display detected clicks on a time-bearing display similar to that shown in Fig. 3.

\section{Post-survey acoustic analysis}

Stored audio files and PAMGuard databases were reprocessed ashore, offline, after each survey using PAMGuard which was configured to detect odontocete clicks with energy in the $2 \mathrm{kHz}$ to $150 \mathrm{kHz}$ band on the recordings from the high frequency hydrophone elements, and to measure bearings for transient detections.

Classifiers were not specifically configured to distinguish sperm whale clicks from other transient signals since the acoustic characteristics of sperm whale clicks received during towed hydrophone surveys are highly variable and are difficult to distinguish from other transient sounds, such as cavitation from propellers. Experience has shown that characteristic sperm whale click trains can be most easily identified visually on the time-bearing display of a PAMGuard click detector (e.g. Fig. 3), based on the appearance and regularity of clicks within long click trains. This was the approach used here.

PAMGuard click display output screens (e.g. Fig. 3) were examined visually. Sequences of clicks thought to be from the same sperm whale were identified and 'marked-up' using tools in PAMGuard. Clicks identified as being part of a sequence from the same individual were also assigned different colours in the display and data summarising each click, including its time, bearing and click-train identity were stored in a database. On some occasions, whales were so closely aggregated that they could not be separated using click bearing information. In this case a single 'train' might contain clicks from several individuals. Generally, close examination of sections of each train clarified how many animals were vocal. However, it was not always possible to assign clicks to individuals over an extended period and localisation might thus be based on information from clicks produced by several animals. This is analogous to standard visual observation-based distance sampling methods where observers identify groups of animals and estimate the group size and the distance to the centre of the group (Barlow et al., 2001; Buckland et al., 2012).

The full dataset was analysed by two experienced analysts. The first performed a complete 'mark-up' of all the acoustic data. These 'marked-up' datasets were then reviewed independently by the second analyst and any potential errors or discrepancies were flagged and discussed between the two analysts to arrive at a consensus interpretation and an agreed final 'marked-up' dataset. Once the analysts were satisfied with this stage of the analysis, the identified sperm whale 


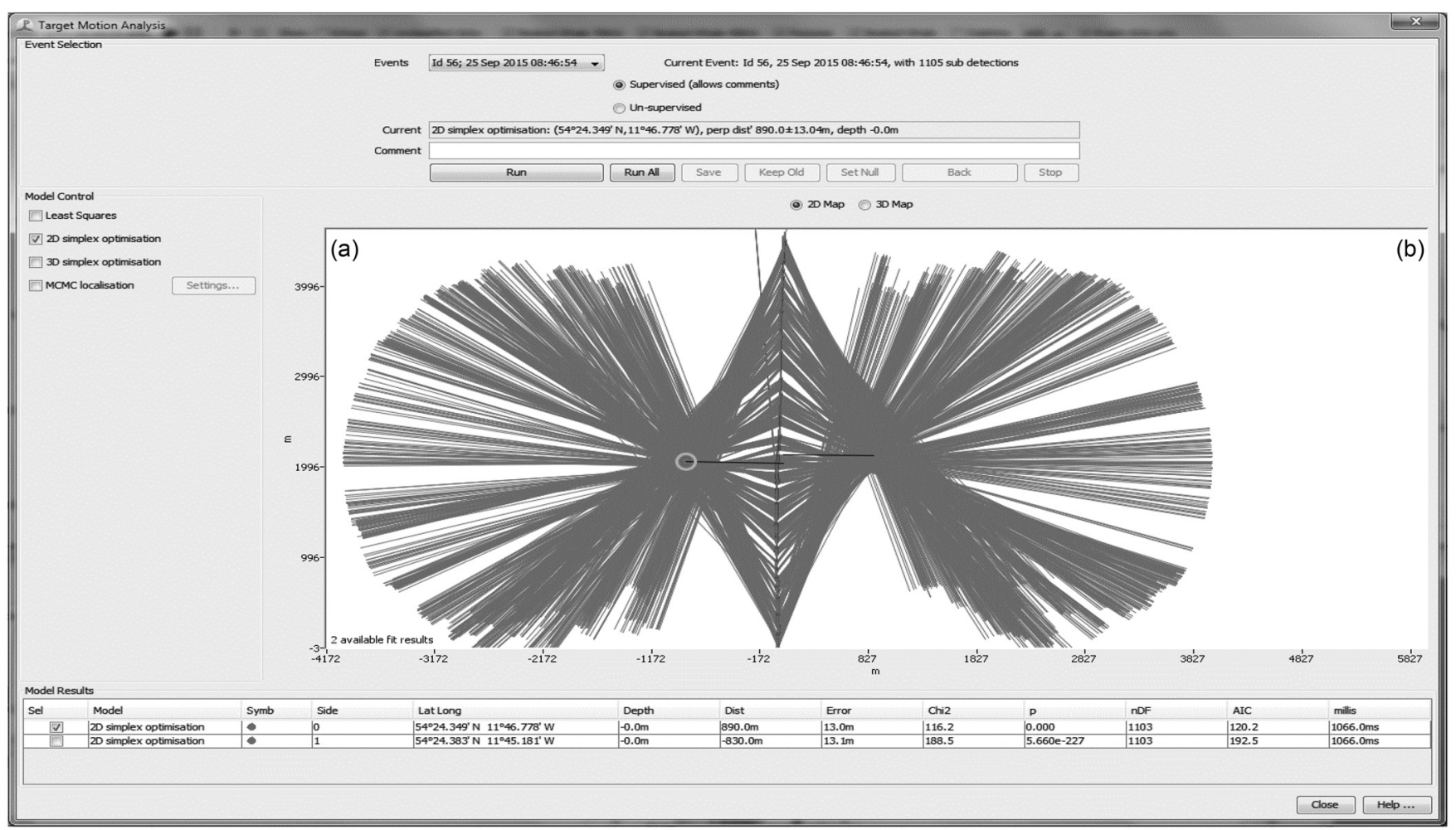

Fig. 4. The target motion analysis module in PAMGuard used for localising sperm whales. In this case the hydrophone is being towed (down the page) past a vocalising whale and a series of 1105 bearings for individual clicks, based on time-of-arrival differences at a pair of hydrophones, are displayed. With a simple two element array there is potential for a left/right ambiguity, so bearings are shown on both the right (a) and the left (b). Two potential locations are calculated at $890 \mathrm{~m}$ and $830 \mathrm{~m}$ from the trackline. The fit for the location on the right-hand side of the vessel (a) is significantly better than for that on the left (b).

click trains were further processed using the PAMGuard target motion analysis (TMA) module. This applied leastsquares optimisation to find the most likely crossing point of bearings for each individual sperm whale (or small group) from different points along the vessel's trackline (Fig. 4). The TMA module used a Simplex optimisation function to determine the animal's location by minimising the sum of the squared differences between the measured and expected bearings from each click to an animal location. A perpendicular distance from the trackline was then calculated for the location with the best fit.

With a simple linear array, such as the one used in this study, there is a tendency for TMA locations to have a left-right ambiguity. Fore and aft bearings are calculated accurately to provide a reliable range from the trackline but it can be unclear whether the sound source is to the left or the right of the trackline. If a change in course is made during an encounter, then this ambiguity can be resolved. For example, in Fig. 4, the bearings on the vessel's starboard side provide a much tighter bearing, with a lower sum of squares, than do those on the port side. It was not always possible to resolve left/right ambiguity in this way, especially in the data obtained from RV Celtic Voyager which maintained a very straight course. However, the information required for distance sampling analysis of line-transect data is simply the distance of detections from the trackline and consequently, for this analysis, this left/right ambiguity was of no consequence.

\section{Sperm whale density estimation}

Acoustically-derived perpendicular distances were processed using Distance software (Thomas et al., 2010) to estimate a detection function, showing how detection probability decreased with range (Fig. 5).
Estimates of density and associated variance were obtained by subdividing the transect lines surveyed into non-overlapping segments of $4 \mathrm{~km}$ length. Density $\hat{D}$ (in individuals $\mathrm{km}^{-2}$ ) was given by

$$
\hat{D}=n /(4 \times e s w) \text {. }
$$

Where $e s w$ is the effective strip width (double the effective strip half-width, eshw), $n$ is the total number of animals detected in each stratum.

Each segment could then be treated as a sampling unit to estimate variance in the total number of animals detected using

$$
\widehat{\operatorname{var}}(n)=k \sum_{i=1}^{k}\left(n_{i}-\frac{n}{k}\right)^{2} /(k-1) \text {. }
$$

Where $n_{i}$ is the number of animals detected and passing abeam in each segment and $k$ is the number of segments (from Buckland et al., 2012).

The proportion of animals directly on the trackline which are detected (often referred to as $g(0)$ ) was assumed to be 1 (see Discussion).

\section{RESULTS}

The number of sperm whale encounters (or 'events') detected in each acoustic line-transect survey varied between 87 and 5 (Table 1). This is likely to reflect differences in seasonal and spatial distribution as well as being due to random effects.

\section{Sperm whale density}

Detection function

Detection functions were calculated separately for the two surveys conducted from RV Celtic Voyager and the four 


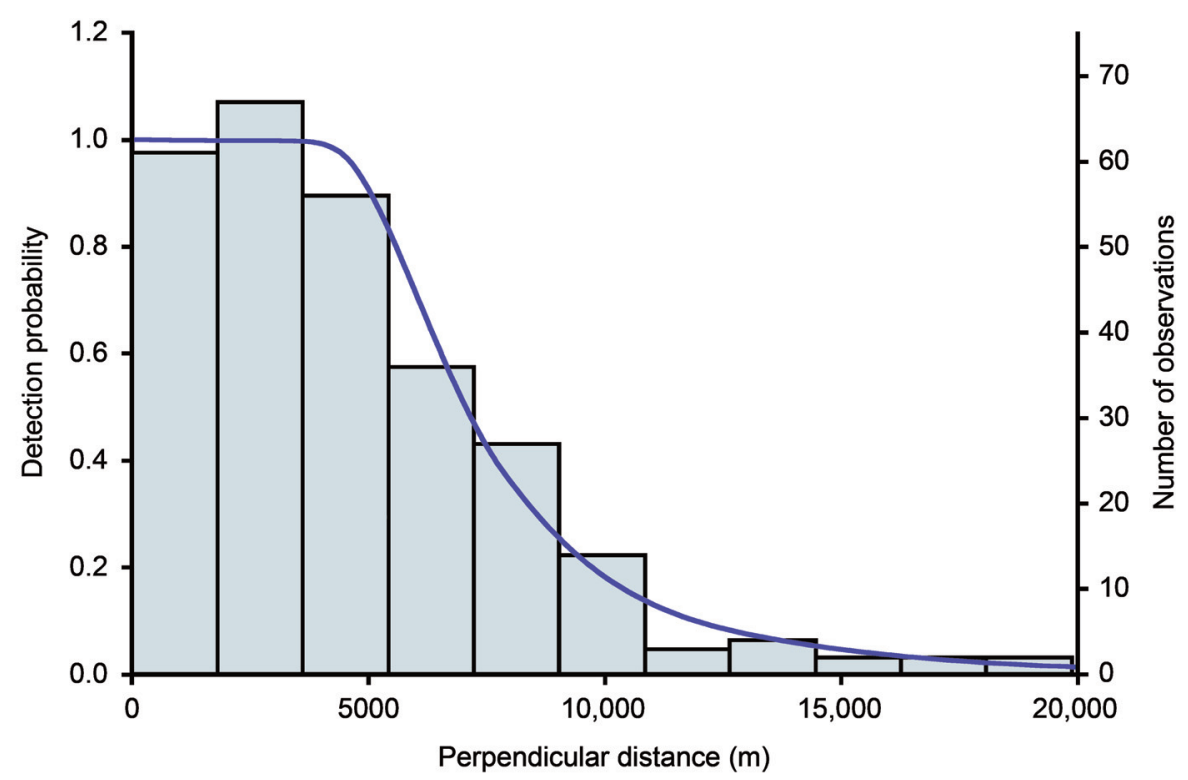

Fig. 5. Hazard rate detection function (blue curve) fitted to sperm whale perpendicular distances (histogram) for RV Song of the Whale and RV Celtic Voyager data combined. The effective strip halfwidth was $7,958 \mathrm{~m}$

Table 2

Estimated effective strip half-width (eshw) for acoustic detections of sperm whales during the study based on hazard rate function fitted to perpendicular distance data using the program Distance.

\begin{tabular}{lrccr}
\hline Data & N & eshw $(\mathrm{m})$ & CV & 95\% CI of eshw \\
\hline RV Song of the Whale & 218 & 8,003 & 0.055 & $7,178-8,922$ \\
RV Celtic Voyager & 58 & 8,140 & 0.087 & $6,364-10,411$ \\
All detections truncated at 20km & 274 & 7,958 & 0.050 & $7,212-8,782$ \\
\hline
\end{tabular}

surveys on board RV Song of the Whale. There were no significant differences in the calculated effective strip halfwidths, despite obvious differences in the size and nature of the two vessels (Table 2). This observation supported the use of the combined dataset to calculate a single detection function for all surveys. The best fit model to these perpendicular distances, a hazard rate key function with two parameters and no adjustments, was chosen on the basis of the minimum Akaike Information Criterion (AIC). This is shown in Fig. 5, giving an effective strip half-width of $7,958 \mathrm{~m}$.

The detection function showed a slight peak away from the transect line. This is a common feature in detection functions from sperm whale acoustic surveys. It can most plausibly be explained by the fact that the bearings calculated from a two-element array are three-dimensional angles with a vertical as well as a horizontal component. Sperm whales are deep-diving animals and at short ranges there can be a significant vertical component in the bearing to vocalising individuals. Consequently, TMA-derived distances for animals vocalising at depth but close, in perpendicular terms, to the vessel's trackline will be significantly greater than the perpendicular distances from the trackline at the sea surface. Because this effect is most pronounced at relatively short ranges, the number of animals close to the trackline is underestimated and the number at slightly greater ranges is inflated. However, as these ranges are very much shorter than the typical detection range, in practice, this issue has little effect on the effective strip half-width. Lewis et al. (2018) examined this issue numerically and showed that the potential bias in density estimates resulting from errors in perpendicular distance estimation due to whales being at depth was negligible.

The estimated strip half-widths derived in this study (Table 2) can be compared with other estimates from acoustic surveys conducted aboard the same vessel (RV Song of the Whale) in the Mediterranean using a similar towed hydrophone system. Lewis et al. (2018) estimated effective strip half-widths of between 6 and 10km for different Mediterranean survey areas, which are consistent with the effective strip half-widths of around $8 \mathrm{~km}$ calculated in this study.

\section{Density estimation}

The estimated density and abundance for each survey block are presented in Table 3 under the assumption that $g(0)$ is 1 (see Discussion). Density estimates ranged from 1 individual per $1,000 \mathrm{~km}^{2}$ in block S2 to 4.6 individuals per $1,000 \mathrm{~km}^{2}$ in block $\mathrm{S} 1$. The overall density estimate for the surveyed area, excluding water depths shallower than $300 \mathrm{~m}$, in which no animals were detected, was 3.2 whales per $1,000 \mathrm{~km}^{2}$. This provided an overall abundance estimate across all surveys combined of 380 individuals in the study area (Table 3 ).

\section{DISCUSSION}

\section{Methodological considerations: effective strip widths and $\mathbf{g}(\mathbf{0})$}

In similar acoustic surveys in the Mediterranean, from one of the survey vessels (RV Song of the Whale) used in this 
study (Lewis et al., 2018) estimated effective strip half widths of $6-10 \mathrm{~km}$ for different survey strata. Our estimate of $8 \mathrm{~km}$ falls within this range but is greater than the $4.2 \mathrm{~km}$ of Fais et al. (2016) also using similar equipment. This difference could be explained by differences in the noise signature of the survey vessel used, which can have a major effect on the detection ranges.

The probability of animals being detected on the trackline $(g(0))$ is often assessed in acoustic surveys for sperm whales using knowledge of the animal's vocal behaviour. During extended phases of foraging, sperm whales spend most of their time underwater performing long, deep feeding dives and producing loud click trains interspersed by extended silent periods as the animals return to the surface to breathe. Analysing data from acoustic recording tags (dTags) deployed on sperm whales in the Gulf of Mexico, Mediterranean Sea and the North Atlantic, Watwood et al. (2006) found that periods of vocalisation typically lasted for 28 mins while mean silent intervals extended for some $17 \mathrm{mins}$. The average vessel speed during the present surveys was approximately $8 \mathrm{kts}$ $\left(15 \mathrm{~km} \mathrm{hr}^{-1}\right)$. Thus, the vessel would travel approximately $4.25 \mathrm{~km}$ during a typical period of silence.

Examination of the detection function showed that the relative detection probability remained at close to one until detections were at a range from the trackline of $5 \mathrm{~km}$ or more, which suggests that if an animal directly on the trackline vocalised at any time when the survey vessel was within $5 \mathrm{~km}$ (i.e. along a $10 \mathrm{~km}$ length of trackline) then it would be detected. Therefore, during normal foraging bouts, no animals on the trackline should have been missed as a result of typical pauses in vocalisation when foraging animals are returning to the surface to breathe. It is known however that, approximately once a day, sperm whales in mixed groups do enter more extended resting periods of several hours duration during which time they are either silent or produce a different vocalisation type, 'codas' (Whitehead, 2003); these vocalisations are not detected at long ranges and are rarely registered during towed hydrophone surveys. Fais et al. (2016) used a modelling approach to calculate $g(0)$ using information on patterns of vocalisation collected by acoustic recording tags (dTags) attached to sperm whales in mixed social groups. Their survey had a very different esw and survey speed than this one, however. Applying the same approach to surveys using RV Song of the Whale, with a similar effective strip width and survey speed to this survey, Lewis et al. (2018) calculated values of $g(0)$ of $0.95-0.96$.
The whales detected during this study were very likely to have been mature males, based on current knowledge of this species. Mature males do not live in stable social groups and there are no reliable published data on patterns in their resting behaviour and vocalisation. We do not believe that the data from mixed groups of females and immature males can be used with confidence to predict male vocal behaviour. Thus, a $g(0)$ of 1 has been assumed, which implies that all animals occurring on the trackline during the course of the study were detected. Of course the real value of $g(0)$ will be slightly less than this and consequently the density estimates calculated here under this assumption are biased downwards somewhat. If and when improved information on the resting and vocalisation behaviour of male sperm whales becomes available, the density estimates provided here could be revised accordingly.

\section{Densities}

Estimated densities of sperm whales in our study area varied between the three survey blocks, from a comparatively low estimate of one individual per $1,000 \mathrm{~km}^{2}$ (Block S2) to a high of 4.6 individuals per $1,000 \mathrm{~km}^{2}$ (Block S1). These observed differences in density are also reflected in detections plotted in Fig. 1 with the northernmost entrance to the Porcupine Seabight and the southwestern margins of the Porcupine Bank recording particularly low detection rates. Inevitably, estimated density per unit area will be higher when the area covered by the survey is restricted to the most suitable habitat. In this case our prior expectation was that densities would be greatest just offshore of the continental shelf break. However, the surveys were designed: (a) to detect a range of offshore cetacean species including deep-diving toothed whales; and (b) to robustly test assumptions around the continental slope's importance, by providing good coverage well inshore and offshore of this feature. Thus, areas where much lower densities of sperm whales might be expected were also included in the design.

In this study, no sperm whales were detected in waters less than $300 \mathrm{~m}$ deep. Furthermore, sperm whales have rarely been reported in continental shelf waters at any locations worldwide. Thus, it is reasonable to consider these shallow waters to be largely outside the natural habitat of the species. For this reason, an overall density for the survey region excluding waters less than $300 \mathrm{~m}$ deep $(3.2$ whales per $1,000 \mathrm{~km}^{2}$ ) was also calculated and is presented in Table 3.

Table 3

Summary of survey effort, acoustic detections of sperm whales, densities and abundance for each survey block and for the total surveyed area with water depth greater than $300 \mathrm{~m}$.

\begin{tabular}{|c|c|c|c|c|}
\hline & Block N & Block S1 & Block S2 & $\begin{array}{l}\text { All segments with minimum } \\
\text { depth deeper than } 300 \mathrm{~m}\end{array}$ \\
\hline Number of $4 \mathrm{~km}$ segments & 853 & 427 & 387 & 1,931 \\
\hline Total count $(n)$ & 202 & 122 & 25 & 391 \\
\hline Sum of segment length $(\mathrm{km})$ & 3,346 & 1,674 & 1,522 & 7,560 \\
\hline Block area $\left(\mathrm{km}^{2}\right)$ & 52,786 & 31,346 & 34,578 & \\
\hline Density (individuals per $1,000 \mathrm{~km}^{2}$ ) & 3.8 & 4.6 & 1.0 & 3.2 \\
\hline $\mathrm{CV}$ of density estimate & 0.13 & 0.21 & 0.34 & 0.04 \\
\hline $95 \%$ CI for density estimate & $3.0-4.8$ & 3. $0-6.9$ & $0.5-2.0$ & $3.0-3.5$ \\
\hline Abundance (individuals) & 200 & 144 & 36 & 380 \\
\hline
\end{tabular}




\section{Comparison with other surveys}

Sperm whales were surveyed acoustically and visually in Atlantic waters to the west of Ireland during the CODA survey in the summer of 2007 (Swift et al., 2009). Acoustic data from one of the CODA survey areas (Block 1), which overlaid the northern survey block for this survey $(\mathrm{N})$, could not be analysed however. The estimated density within CODA survey Block 2, which overlapped with survey blocks S1 and S2 in our study and extended southwards to latitude $45^{\circ} \mathrm{N}$, was 3.3 individuals per $1,000 \mathrm{~km} 2(\mathrm{CV}=0.2)$. Visually-based density estimates for the same block were lower at 2 individuals per $1,000 \mathrm{~km}^{2}$ (Hammond et al., 2009). Both density estimates were similar to our estimates for blocks S1 and S2 of 4.6 and 1.0 individuals per $1,000 \mathrm{~km}^{2}$ respectively. The visually-based density estimate derived from CODA data for Block 1, which overlapped with Block $\mathrm{N}$ in the present survey was 1 whale per $1,000 \mathrm{~km}^{2}$ compared to the Block $\mathrm{N}$ acoustically-derived density of 3.8 whales per $1,000 \mathrm{~km}^{2}$. However, appropriate care must be taken when comparing and interpreting density data for deep-diving species gathered by such different methodologies and also between differing seasons and years.

It is nevertheless evident from this study that Irish Atlantic offshore waters, particularly those along and beyond the continental shelf break, provide important habitats for sperm whales. This supports and augments earlier findings via acoustic and visual means (Aguilar de Soto et al., 2004; Ó Cadhla et al., 2004). Given current knowledge of this large predatory species in the northeast Atlantic this area of high sperm whale density is likely connected to other apparent high-density areas in UK offshore waters, e.g. Wyville Thompson Ridge and Faroe-Shetland Channel (Embling, 2007; Hastie et al., 2001; Lewis et al., 1998) and further afield. The average densities presented here are somewhat similar to those reported via acoustic surveys among known concentrations of sperm whales further south in the North Atlantic. For example, Swift et al. (2009) reported densities of 4.6 and 3.6 animals per $1,000 \mathrm{~km}^{2}$ off northwest Spain $\left(42^{\circ}\right.$ to $\left.45^{\circ} \mathrm{N}\right)$ and in the Bay of Biscay $\left(44^{\circ}\right.$ to $\left.48^{\circ} \mathrm{N}\right)$ respectively. Leaper et al. (1992) reported a density of 5.9 animals per $1,000 \mathrm{~km}^{2}$ for the Azores $\left(38^{\circ}\right.$ to $\left.39^{\circ} \mathrm{N}\right)$ while Fais et al. (2016) reported a density of 4.24 animals per $1,000 \mathrm{~km}^{2}$ for waters around the Canary Islands off northwest Africa $\left(27^{\circ}\right.$ to $\left.31^{\circ} \mathrm{N}\right)$. Hastie et al. (2003) reported slightly lower mean densities of 1.44 whales per $1,000 \mathrm{~km}^{2}$ in the FaroeShetland Channel to the north of the study area.

\section{Management implications}

Clearly the area surveyed in this study, often called 'Ireland's Atlantic Margin' provides important foraging habitats for sperm whales. This offshore region is an increasing focus of interest for hydrocarbon exploration (Wrigley et al., 2014). It is considered a 'frontier area' in a European context and is relatively under-explored in industry terms. Among the first steps in offshore exploration for hydrocarbons are the completion of 2D and 3D seismic surveys in order to identify potential oil/gas prospects and to inform industry on the nature of the seabed and the underlying stratigraphy and crust structure.

As deep-diving cetaceans that are heavily reliant on the production and reception of sound underwater for many aspects of their ecology and social behaviour, sperm whales may be particularly vulnerable to acoustic masking (i.e. signal interference) and disturbance from acoustic signals produced by seismic airgun arrays. They are believed to have better hearing sensitivity than other odontocete species at lower acoustic frequencies which dominate noise from airgun arrays used in seismic surveys. Sperm whales have previously been reported to respond negatively to seismic surveys (Mate et al., 1994). Miller et al. (2009) reported evidence of reduced foraging rates in sperm whales exposed to airguns in the Gulf of Mexico while Farmer et al. (2018) suggest that such effects could have negative population consequences for sperm whales in that area.

Based on the present study, improved understanding of sperm whale density and distribution within the Atlantic Margin derived by acoustic methods, will be immediately important for the assessment, management and mitigation of any future risks introduced by maritime exploration. Under the EC Habitats Directive there is an obligation on all EU member states to provide a system of strict protection for all cetacean species (as Annex IV species). In an Irish context, measures to assess, manage and mitigate risks to cetaceans arising from underwater sound include the adoption of guidance principles and mitigation protocols (e.g. DAHG, 2014), as well as time-based or area-based management of activities by the relevant Regulatory Authority.

Sperm whales in the Atlantic are known to feed on a range of deep-water fish and squid (Santos et al., 2002). In many parts of the world, sperm whales have learned to depredate from long lines, resulting in economic impacts for fisheries and in an increased entanglement risk for the whales. In the Atlantic heavy sperm whale depredation was reported from fisheries for halibut (Reinhardtius hippoglossoides) around Greenland during the 1990s (Dyb, 2006), while currently depredation is becoming increasingly prevalent in a Norwegian coastal longline fishery targeting the same species (Tiu Similä, pers. comm.). There have been no reports of depredation incidents in Irish waters thus far, although long-lining, undertaken mainly by Spanish and UK registered vessels, is a common high seas fishery practice.

In such contexts, a sustainable, workable balance must be found between human maritime and resource extraction interests and the prevailing nature conservation interests, such that important marine biodiversity and ecosystem integrity can be maintained.

\section{ACKNOWLEDGEMENTS}

This work was carried out as part of the ObSERVE Acoustic project (2015-18) under the Irish Government's ObSERVE Programme established in 2014. The programme is an initiative developed and designed by the Department of Communications, Climate Action and Environment (DCCAE) in partnership with the Department of Culture, Heritage and the Gaeltacht (DCHG). We would like to thank the ObSERVE contract management team for their advice and support during this project, for DCCAE: Bill Morrissey, Louise Casey, Clare Morgan, Aoife O’Connor, Ciarán Ó hÓbáin, Orla Ryan, Keith Flanagan and Ciaran McManus; for DCHG: Dr Ferdia Marnell and Dr Eamonn Kelly; and also Greg Donovan of the International Whaling 
Commission. Thanks also to the Irish Whale and Dolphin Group visual observers, Michael Marrinan, John Collins, Darren Craig, Laurence Manning, Stephanie Levesque, Enda McKeogh, John Power, Sean O'Callaghan, Inês Cunha and Catherine O'Sullivan, and to the SMRU Consulting PAM operators, Jamie Macaulay and Chloe Malinka. We would also like to thank the Captains and crew of RV Celtic Voyager and RV Song of the Whale for providing support during the towed hydrophone surveys. This research was conducted under contract to Ireland's Department of Communications, Climate Action and Environment in partnership with the Department of Culture, Heritage and the Gaeltacht.

\section{REFERENCES}

Aguilar de Soto, N., Rogan, E., Ó Cadhla, O., Gordon, J.C.D., Mackey, M. and Connolly, N. 2004. Cetaceans and seabirds of Ireland's Atlantic Margin. Volume III - Acoustic surveys for cetaceans. Report on research carried out under the Irish Infrastructure Programme (PIP): Rockall Studies Group (RSG) projects 98/6 and 00/13, Porcupine Studies Group project P00/15 and Offshore Support Group (OSG) project 99/38. 51pp.

Avila de Melo, A.M. and Martin, A.R. 1985. A study of male sperm whale length data from the Azorean and Madeiran catches, 1947-82. Rep. Int. Whal. Commn 35:209-15.

Barlow, J., Gerrodette, T. and Forcada, J. 2001. Factors affecting perpendicular sighting distances on shipboard line-transect surveys for cetaceans. J. Cetacean Res. Manage. 3(2):201-12.

Barlow, J. and Taylor, B.L. 2005. Estimates of sperm whale abundance in the northeastern temperate Pacific from a combined acoustic and visual survey. Mar. Mammal Sci. 21(3):429-45.

Berrow, S. and O'Brien, J. 2005. Sperm whale Physeter macrocephalus L. calf, live stranded in Co Clare. Ir. Nat. J. 28(1): 40-41.

Berrow, S.D. and Rogan, E. 1997. Review of cetaceans stranded on the Irish Coast, 1901-1995. Mammal Review 27(1):51-76.

Brown, S.G. 1976. Modern whaling in Britain and the north-east Atlantic Ocean. Mammal Review 6(1):25-36.

Buckland, S.T., Anderson, D.R., Burnham, K.P. and Laake, J.L. 2012. Distance Sampling: Estimating Abundance of Biological Populations. Springer Science + Business Media Germany and New York. 446pp.

Department Arts, Heritage and Gaelacht (DAHG). 2014. Guidance to manage the risk to marine mammals from man-made sound sources in Irish waters. National Parks and Wildlife Service of the Department of Arts, Heritage and Gaeltacht, Dublin. 59pp. [Available at: https://www.npws.ie/sites/default/files/general/Underwater\%20sound\%2 Oguidance Jan\%202014.pdf].

Davies, A.J., Roberts, J.M. and Hall-Spencer, J. 2007. Preserving deep-sea natural heritage: Emerging issues in offshore conservation and management. Biol. Cons. 138(3-4):299-312.

Doughty, C.E., Roman, J., Faurby, S., Wolf, A., Haque, A., Bakker, E.S., Malhi, Y., Dunning, J.B. Jr. and Svenning, J.-C. 2016. Global nutrient transport in a world of giants. Proc. Natl Acad. Sci. USA 113(4):868-73.

Dyb, J.E. 2006. Fisheries depredation experience of the Norwegian longline fleet. Paper presented to the Symposium on Fisheries Depredation by Killer and Sperm Whales: Behavioural Insights, Behavioural Solutions, Vancouver, British Columbia, October 2006 (unpublished). 3pp. [Available from: http://www.vanaqua.org/depredation/Documents/JanErikExtendedAbstractNorwegianlonglinefleet.kh.pdf]

Embling, C.B. 2007. Predictive models of cetacean distributions off the west coast of Scotland. PhD thesis, University of St. Andrews, Scotland. 280pp. [Available at: https://research-repository.st-andrews.ac.uk/ bitstream/handle/10023/640/Clare\%20B\%20Embling\%20PhD\%20thesis. $p d f ?$ sequence $=6$ \&is Allowed $=y]$.

Evans, P.G.H. 1997. Ecology of sperm whales (Physeter macrocephalus) in the eastern North Atlantic, with special reference to sightings and strandings records from the British Isles. Biologie in Unserer Zeit. 67(Suppl.):37-46.

Fairley, J. 1981. Irish Whales and Whaling. Blackstaff Press, Belfast. 218pp. Fais, A., Lewis, T.P., Zitterbart, D.P., Ivarez, O. and Aguilar de Soto, N 2016. Abundance and distribution of sperm whales in the Canary Islands: are ship-strikes sustainable? PLOS ONE 11(3):e0150660.

Farmer, N.A., Baker, K., Zeddies, D.G., Denes, S.L., Noren, D.P., Garrison, L.P., Machernis, A., Fougères, E.M. and Zykov, M. 2018. Population consequences of disturbance by offshore oil and gas activity for endangered sperm whales Physeter macrocephalus. Biol. Cons. 227:189204.
Gillespie, D., Gordon, J., McHugh, R., McLaren, D., Mellinger, D., Redmond, P., Thode, A., Trinder, P. and Deng, X.Y. 2008. PAMGUARD: Semi-automated, open source software for real-time acoustioc detection and localisation of cetaceans. Proc. I.O.A. 30(5):9.

Gordon, J.C., Gillespie, D., Potter, J.J., Frantzis, A., Simmonds, M.P., Swift, R. and Thompson, D. 2003. A review of the effects of seismic surveys on marine mammals. Mar. Tech. Soc. J. 37(4):16-34.

Hammond, P.S., MacLeod, K., Gillespie, D., Swift, R., Winship, A., Burt, M.L., Cañadas, A., Vázquez, J.A., Ridoux, V., Certain, G., Van Canneyt, O., Lens, S., Santos, B. and Rogan, E. 2009. Cetacean offshore distribution and abundance in the European Atlantic (CODA). 43pp without appendices; $164 \mathrm{pp}$ with appendices. [Available from: http:// biology.st-andrews.ac.uk/coda/documents/CODA_Final_Report_112-09.pdf]

Harwood, J. and Wilson, B. 2001. The implications of developments on the Atlantic Frontier for marine mammals. Cont. Shelf Res. 21:107393.

Hastie, G.D., Gordon, J., Swift, R. and Heath, M. 2001. Feasibility report into the use of passive acoustics to study odontocetes from the FRS research vessel, Scotia, in the northeast Atlantic. Unpublished report submitted to Shell (UK). 12pp. [Available from the author]

Hastie, G.D., Swift, R.J., Gordon, J.C.D., Slesser, G. and Turrell, W.R. 2003. Sperm whale distribution and seasonal density in the Faroe Shetland Channel. J. Cetacean Res. Manage. 5(3):247-52.

Katona, S. and Whitehead, H. 1988. Are cetacea ecologically important? Oceanogr. Mar. Biol. Annual Review 26:553-68.

Lavery, T.J., Roudnew, B., Gill, P., Seymour, J., Seuront, L., Johnson, G., Mitchell, J.G. and Smetacek, V. 2010. Iron defecation by sperm whales stimulates carbon exportin the Southern Ocean. Proc. R. Soc. B: Biol. Sci. 277:3527-31

Leaper, R., Chappell, O. and Gordon, J. 1992. The development of practical techniques for surveying sperm whale populations acoustically. Rep. Int. Whal. Commn 42:549-60.

Leaper, R., Gillespie, D., Gordon, J. and Matthews, J. 2003. Abundance assessment of sperm whales. Paper SC/55/O13 presented to the IWC Scientific Committee, May 2003, Berlin (unpublished). 5pp. [Paper available from the Office of this Journal].

Leaper, R., Gillespie, D. and Papastavrou, V. 2000. Results of passive acoustic surveys for odontocetes in the Southern Ocean. J. Cetacean Res. Manage. 2(3):187-96.

Lewis, T., Gillespie, D., Lacey, C., Matthews, J., Danbolt, M., Leaper, R., McLanagan, R. and Moscrop, A. 2007. Sperm whale abundance estimates from acoustic surveys of the Ionian Sea and Straits of Sicily in 2003. J. Mar. Biol. Assoc. U.K. 87:353-57.

Lewis, T., Matthews, J., Boisseau, O., Danbolt, M., Gillespie, D., Lacey, C., Leaper, R., McLanaghan, R. and Moscrop, A. 2018. Abundance estimates for sperm whales in the south western and eastern Mediterranean Sea from acoustic line-transect surveys. J. Cetacean Res. Manage. 18:10317.

Lewis, T.P., Swift, R., Gonzalbes, P., Butler, J. and Gordon, J. 1998. Passive Acoustic Monitoring of Cetacean Distribution North-West of the Hebrides. Hebridean Whale and Dolphin Trust, Mull. 75pp.

Mate, B.R., Stafford, K.M. and Ljungblad, D.K. 1994. A change in sperm whale (Physeter macrocephalus) distribution correlated to seismic surveys in the Gulf of Mexico. J. Acoust. Soc. Am. 96(5):3268-69.

Miller, P.J.O., Johnson, M.P., Madsen, P.T., Biassoni, N., Quero, M. and Tyack, P.L. 2009. Using at-sea experiments to study the effects of airguns on the foraging behavior of sperm whales in the Gulf of Mexico. Deep Sea Res. I. 56(7): 1,168-81.

Ó Cadhla, O., Mackey, M., Aguilar de Soto, N., Rogan, E. and Connolly, N. 2004. Cetaceans and seabirds of Ireland's Atlantic Margin. Volume II - Cetacean distribution and abundance. Report on research carried out under the Irish Infrastructure Programme (PIP): Rockall Studies Group (RSG) projects 98/6 and 00/13, Porcupine Studies Group project P00/15 and Offshore Support Group (OSG) project 99/38. 82pp.

Pike, D.G., Gunnlaugsson, T., Víkingsson, G.A. and Mikkelsen, B. 2008. Estimates of the abundance of fin whales (Balaenoptera physalus) from the T-NASS Icelandic and Faroese ship surveys conducted in 2007. Paper SC/60/PFI13rev presented to the IWC Scientific Committee, June 2008, Santiago, Chile (unpublished). 16pp. [Paper available from the Office of this Journal].

Reid, J.B., Evans, P.G.H. and Northridge, S.P. 2003. Atlas of Cetacean Distribution in North-west European Waters. Joint Nature Conservation Committee, Peterborough, UK. 76pp.

Rogan, E., Cañadas, A., Macleod, K., Santos, M.B., Mikkelsen, B., Uriarte, A., Van Canneyt, O., Antonio Vázquez, J. and Hammond, P.S. 2017. Distribution, abundance and habitat use of deep diving cetaceans in the North-East Atlantic. Deep Sea Res. II. 141:8-19.

Santos, M.B., Pierce, G.J., García Hartmann, M., Smeenk, C., Addink, M.J., Kuiken, T., Reid, R.J., Patterson, I.A.P., Lordan, C., Rogan, E. and Mente, 
E. 2002. Additional notes on stomach contents of sperm whales Physeter macrocephalus stranded in the north-east Atlantic. J. Mar. Biol. Assoc. U.K. 82(3):501-07.

Stone, C.J. 2015. Marine mammal observations during seismic surveys from 1995-2010. JNCC Report 463a.

Swift, R.J., Gillespie, D., Vázquez, J.A., MacLeod, K. and Hammond, P.S. 2009. Appendix IV, Abundance of sperm whales (Physeter macrocephalus) estimated from acoustic data for Blocks 2, 3 and 4 (French and Spanish sectors). Cetacean Offshore Distribution and Abundance in the European Atlantic (CODA). Report available from SMRU, Gatty Marine Laboratory, University of St. Andrews, St. Andrews, Fife KY16 8LB, UK.

Thomas, L., Buckland, S.T., Rexstad, E.A., Laake, J.L., Strindberg, S., Hedley, S.L., Bishop, J.R.B., Marques, T.A. and Burnham, K.P. 2010. Distance software design and analysis of distance sampling surveys for estimating population size. J. Appl. Ecol. 47(1):5-14.

Tønnessen, J.N. and Johnsen, A.O. 1982. The History of Modern Whaling. C. Hurst and Co., London. $\mathrm{i}-\mathrm{xx}+798 \mathrm{pp}$

Wall, D., Murray, C., O’Brien, J., Kavanagh, L., Wilson, C., Ryan, C., Glanville, B., Williams, D., Enlander, I., O'Connor, I., McGrath, D.,
Whooley, P. and Berrow, S. 2013. Atlas of the Distribution and Relative Abundance of Marine Mammals in Irish Offshore Waters: 2005-2011. Irish Whale and Dolphin Group, Merchants Quay, Kilrush, County Clare, Ireland. 58pp.

Watwood, S.L., Miller, P.J.O., Johnson, M., Madsen, P.T. and Tyack, P.L. 2006. Deep-diving foraging behaviour of sperm whales (Physeter macrocephalus). J. Anim. Ecol. 75(3):814-25.

Weir, C.R., Pollock, C.M., Cronin, C. and Taylor, S. 2001. Cetaceans of the Atlantic Frontier, north and west of Scotland. Cont. Shelf Res. 21(810):1,047-71.

Whitehead, H. 2003. Sperm Whales: Social Evolution in the Ocean. University of Chicago Press, Chicago. 464pp.

Whitehead, H. and Gordon, J. 1986. Methods of obtaining data for assessing and modelling sperm whale populations which do not depend on catches. Rep. Int. Whal. Commn (special issue) 8:149-65.

Wright, A.J. and Mel Cosentino, A. 2015. JNCC guidelines for minimising the risk of injury and disturbance to marine mammals from seismic surveys: We can do better. Mar. Pollut. Bull. 100:231-39.

Wrigley, R., Rodriguez, K. and Intawong, A. 2014. Ireland Atlantic Margin: a new era in a frontier basin. First Break 32:95-100. 